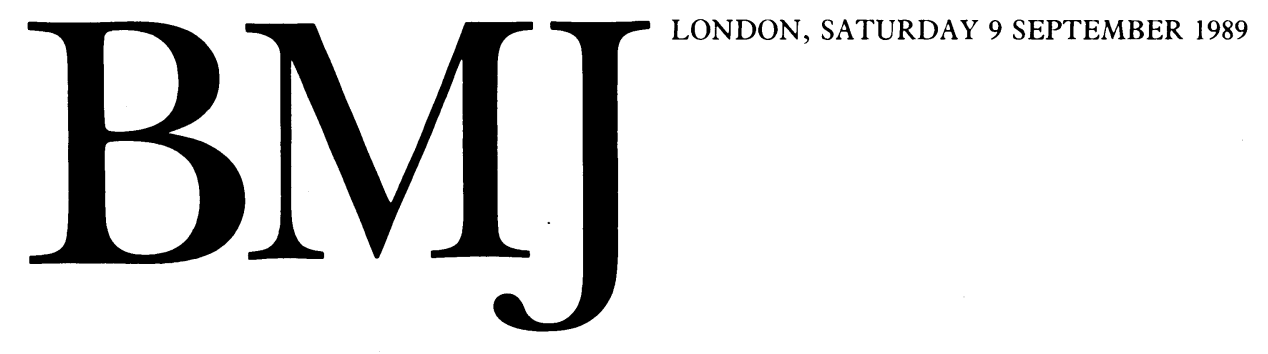

\title{
Management of old people with neck trauma
}

\author{
Injury to the cervical cord is common but may be overlooked
}

The first important requirement in managing any patient with an injury to the cervical spine is to make the diagnosis: failure to do this in a patient with traumatic spinal instability may lead to increased neurological deficit. In one large series of such injuries the diagnosis was missed in the accident and emergency department in one third of cases. ${ }^{1}$ Just under two thirds of cervical spine injuries occur in the second, third, and fourth decades of life, and most are in men hurt in road traffic accidents, falls, or sporting accidents. When they occur at the top end of the age range the injuries have special features.

In the elderly any cervical degenerative disease may cause anatomical, if not clinical, compromise of the cervical cord, making it more susceptible to damage caused by excessive movement. An injury to the cervical spine may lead to complete or incomplete lesions of the anterior cord or hemicord or damage to the central cord. We should distinguish those older patients who have survived for several decades after a spinal injury from those patients in whom the injury occurs after the age of 55 or 60 years ( $F$ W Meinke, paper to the International Medical Society of Paraplegia 28th annual scientific meeting, Rome, 1989).

Injury to the cervical spine may be obvious when there is a history of a fall while horse riding or diving into the shallow end of a swimming pool. In other circumstances it may be less clear that the cervical spine is damaged, but suspicions should be aroused, for instance, if after a traffic accident there are injuries to the head and face together with those to the trunk or arm. Clearly the part in the middle-the cervical spinemay also be damaged in such cases. Injury to the cervical spine produces a tense, painful neck that may be locally tender. A good quality lateral $x$ ray film of all seven cervical vertebrae is mandatory for such patients. From this an experienced radiologist will be able to see, or at least strongly suspect, most cervical spine injuries. Once the diagnosis has been made the patient is immobilised and more elaborate investigation such as dynamic $x$ ray views of the cervical spine, computed tomography combined with myelography, or magnetic resonance imaging carried out. After reduction and realignment the spine is stabilised either internally or externally. Damage to the cervical spine does not always damage the spinal cord, but in cooperative patients a few questions about sensory and motor function are often enough to indicate whether cord damage has occurred.

The protocol for the early stages of management of an elderly patient with cervical spine trauma does not differ substantially from that followed for younger patients. There are, however, important differences as a result of the response of the elderly patient to spinal cord damage. Prolonged periods of immobilisation are bad for all patients, but especially for the elderly. The problems of recumbency enforced by an injury to the spinal cord may be reduced by early stabilisation of the cervical spine followed by mobilisation of the patient - as the neurological deficit permits. Older people are more likely to have pre-existing medical conditions. If respiratory compromise secondary to spinal cord damage is superimposed on chronic obstructive airways disease then ventilation or tracheostomy may be needed. Loss of sympathetic tone and maintenance of vagal activity may combine to produce hypotension and bradycardia-a pattern that correlates with recovery in patients who have an incomplete spinal cord lesion. ${ }^{2}$ Post-traumatic autonomic dysfunction may complicate existing cardiac arrhythmia or myocardial ischaemia or cause poor tissue perfusion in a patient with hypertension. In general, the medical complications of spinal cord damage in elderly patients are of a kind to bring home to the surgeon the desirability of cooperation with the resources of a spinal injury unit at an early stage. How aggressive the management should be of the elderly patient who has a complete cervical spine lesion is likely to be a function of the perceived achievable level of independence, the patient's life expectancy, and open communication with those directly concerned. ${ }^{3}$

The syndrome of acute central injury to the cervical spinal cord is mainly, but not exclusively, an injury of older people with pre-existing degenerative disease of the spinal canal. It was first described by Schneider in $1954 .{ }^{45}$ Between 1979 and $1983,15 \%$ of patients ( 24 of 158 ) admitted to the West of Scotland Spinal Injuries Unit had this lesion ( $M$ Delargy, personal communication). Their mean age was 59 , and most were men; 17 were injured as a result of a simple fall, and five had had road traffic accidents. In a retrospective study Shibaski and Otani found that $35 \%$ of cervical cord injuries in patients over 65 years were of the central type (paper to International Medical Society of Paraplegia 27th annual scientific meeting, Perth, Australia, 1988). This injury is caused by hyperextension of the neck in a patient whose cervical spinal canal has already been reduced in size by degenerative disease. Central damage results when the spinal cord is suddenly compressed between anterior cervical osteophytes or a disc and the inward buckling of the posterior ligamentum flavum. ${ }^{26}$ Damage to the central grey matter affects anterior horn cells at the level of the lesion and spreads 
to the lateral corticospinal and spinothalamic tracts. As the legs are represented laterally in these tracts their axons are relatively spared. ${ }^{2}$ The patient has a characteristic presentation with disproportionately greater weakness of the arms than of the legs, a variable sensory loss, and often a tell tale abrasion of the forehead. ${ }^{5}$ This diagnostic pointer is the topic of the lesson of the week on $p 669$. A plain radiograph of the cervical spine will show osteophyte formation but no fracture or dislocation.

With non-surgical management about half of patients with central cervical cord injury make a useful functional recovery, and Schneider and Schemm suggested that surgical decompression had no part to play in this injury. ${ }^{2}$ Bohlmann, too, found that half the patients with this syndrome treated conservatively were able to walk; he also observed that the single patient who had an acute prolapse of the cervical disc made a complete recovery after its surgical removal. ' Nevertheless, he reported that laminectomy was associated with increased rates of neurological deficit and mortality. The extent of early recovery is an indicator of the eventual outcome and probably reflects the amount of local damage to the spinal cord. Recovery of function in the legs is better than that in the arms, but poor grip strength causes reduced mobility if a walking aid cannot be handled satisfactorily.

Young et al drew attention to cervical disc prolapse in elderly patients with cervical spondylosis, though their patients presented with spastic quadriparesis indicating an anterior cord syndrome. ${ }^{7}$ Recent studies with high resolution magnetic resonance imaging have shown that a surprisingly high proportion of patients with acute lesions of the central cervical cord have prolapsed cervical discs (M Piazza, paper to
Cervical Spine Society European Section 6th annual meeting, St Gallen, Switzerland, 1989; B E Northrup, personal communication). The series by Piazza showed that $47 \%$ of patients with central cord lesions had a substantial prolapse of a cervical disc, though the average age of their patients was only 31 . This finding must make us consider whether the elderly patient who develops a central cord lesion has such a disc prolapse and whether its removal will improve the outcome. It seems reasonable to suppose that it might, and some authors have suggested that anterior decompression is beneficial to patients with this injury. ${ }^{8}$ No controlled study of anterior decompressive surgery in central cervical cord injury has been carried out to answer this question. Nevertheless, better imaging and earlier diagnosis may generate a more active response in the management of patients with acute injuries to the central cervical cord.

Consultant Neurosurgeon,

R A JOHNSTON

Institute of Neurosurgical Sciences,

Southern General Hospital,

Glasgow G51 4TF

1 Bohlmann HH. Acute fractures and dislocations of the cervical spine: an analysis of 300 hospitalised patients and review of the literature. $f$ Bone foint Surg $[A m] 1979 ; 61: 1119-42$.

patients and review of the literature. F Bone foint Surg [Am] 1979;61:1119-42. Bohlmann HH, Ducker TB, Lucas JT. Spine and spinal cord injure
FA, eds. The spine. Philadelphia: W B Saunders, 1982:661-756.

3 Mesard L. Survival after spinal cord trauma. Arch Neurol 1978;35:78-83.

4 Schneider RC, Cherry G, Pantek H. The syndrome of acute central cervical spinal cord injury. I Neurosurg 1954;11:546-77.

Schneider RC, Schemm GW. Vertebral insufficiency in acute and chronic spinal trauma. $\mathcal{F}$ Neurosurg $1961 ; 18: 348-60$.

6 Taylor AR. The mechanism of injury to the spinal cord in the neck without damage to the vertebral column. I Bone foint Surg [Br] 1951;33:543-7.

Young S, Tamas L, O'Laoire S. Prolapse of a cervical disc in elderly patients with cervical spondylosis. Br Med f 1986;293:749-80.

Brodkey JS, Miller CF, Harmody RM. The syndrome of acute central cervical spinal cord injury revisited. Surg Neurol 1980;14:251-75.

\section{Our dirty towns}

\section{Uncollected refuse and discarded litter}

Visitors to Britain must be appalled by the amount of refuse lying around the streets of London and other big cities. Elsewhere in Europe cities are cleaned regularly and efficiently.

Houses, shops, and restaurants require a regular system of refuse collection if the environment around them is to be kept clean and reasonably healthy. Local authorities have a statutory duty to provide an adequate and efficient system of refuse collection, yet many - especially in urban areas - seem unable to do so. In the past householders, shops, and small businesses could depend on a regular collection of their refuse at least weekly. Today collections are irregular and sometimes non-existent for weeks. Heaps of refuse in burst plastic bags pile up on pavements and alleyways. These encourage infestation by rats and cats and an increase in the fly population. The vermin may help spread gastrointestinal infections and other diseases, and the heaps are an accident hazard to children. Since the war, the contents of domestic refuse have changed. Formerly it included ashes, rags, paper, glassware, crockery, and metal, together with kitchen waste. The ash content has been reduced with the welcome abandonment of uneconomic and dirty coal fires as a means of warming houses. The kitchen waste content has also been reduced by the sale of already cleaned vegetables. But the dry refuse content has been increased by the addition of all sorts of packaging materials, largely consisting of plastics. The new materials are not biodegradable and will reduce the natural composting which takes place in landfill sites over several years.
The main problem with domestic and commercial refuse is then, one of failure to provide regular and hygienic collection. The blame lies partly with local politicians and partly with the public service trade unions. Many city fathers seem to have forgotten that local authorities came into being to protect the environment from "nuisances." The early medical officers of health such as Dr Duncan of Liverpool, believed that epidemics originated from heaps of rotting organic material. Although microbiological research showed that this concept was false, heaps of refuse are not only aesthetically undesirable they also provide breeding grounds for vermin and parasites. The task of collecting the rubbish has been bedevilled by problems with the workforce, which have seen many prolonged strikes. City dwellers have become familiar with the accumulation of heaps of black garbage bags during these disputes. So-called productivity schemes seem to the citizen to have resulted in less frequent and less reliable collections. Yet refuse collection is no longer a dirty job, it is a physical job with good provision for the health and safety of the operatives.

But policy failure has encouraged local authorities to employ private contractors, and some have had a measure of success. But overall the past decade has seen a decline in the quality of refuse collection. We believe that local authorities need to remember that efficient refuse collection should be a priority duty and one which requires adequate funds and firm management.

Fortunately a bright star has appeared in the gloom - namely, the campaign for recycling refuse. As environmentalists have begun urging us to waste less, local authorities 